\title{
A group contribution method for estimating the vapour pressures of $\alpha$-pinene oxidation products
}

\author{
M. Capouet and J.-F. Müller \\ Belgian Institute for Space Aeronomy, 1180 Brussels, Belgium \\ Received: 13 September 2005 - Published in Atmos. Chem. Phys. Discuss.: 3 November 2005 \\ Revised: 28 February 2006 - Accepted: 2 March 2006 - Published: 8 May 2006
}

\begin{abstract}
A prediction method based on group contribution principles is proposed for estimating the vapour pressure of $\alpha$-pinene oxidation products. Temperature dependent contributions are provided for the following chemical groups: carbonyl, nitrate, hydroxy, hydroperoxy, acyl peroxy nitrate and carboxy. On the basis of observed vapour pressure differences between isomers of diols and dinitrates, a simple refinement is introduced in the method to account for the influence of substitutions on the vapour pressure for alcohols and nitrates. The vapour pressures predicted with this new method have been compared with the predictions from UNIFAC (Asher et al., 2002). Given the large uncertainties of the vapour pressure data for the least volatile compounds, further experimental studies of subcooled vapour pressures of multifunctional compounds at ambient temperatures are required for better parameterizations. Among the $\alpha$-pinene products identified to date, pinic acid and hydroxy pinonic acid are predicted to be the least volatile compounds, with estimated vapour pressures of $3 \times 10^{-6}$ torr and $6 \times 10^{-7}$ torr, respectively. The vapour pressure of the other primary products range from $10^{-5}$ to $10^{-3}$ torr, with hydroxy hydroperoxides presenting the lowest values. Noting that multifunctional carboxylic acids, in particular pinic acid, are believed to be mostly present as dimers in laboratory conditions, we suggest that the partial vapour pressure of the pinic acid dimer should be close to the experimental subcooled vapour pressure for pinic acid (estimated at $\sim 10^{-6}$ torr) due to its large contribution to the total concentration (dimer+monomer) in experimental conditions.
\end{abstract}

\section{Introduction}

Monoterpenes are important constituents of biogenic VOC emissions. Among the monoterpenes, $\alpha$-pinene is observed

Correspondence to: $\mathrm{M}$. Capouet

(manu.capouet@aeronomie.be) to have the highest emission rates and to be the most abundant (Guenther et al., 1995). The vapour pressures of its oxidation products range from $10^{-2}$ torr to $10^{-7}$ torr (Hallquist et al., 1997; Hoffmann et al., 1997; Bilde and Pandis, 2001). The least volatile of these products can enter the aerosol phase and form secondary organic aerosol (SOA) (Kanakidou et al., 2005). The partitioning of a compound $i$ between the gas and aerosol phases has been parameterized by Pankow (1994a,b):

$K_{p, i}=\frac{760 R T f_{o m}}{M W_{o m} 10^{6} \zeta_{i} p_{L, i}^{0}}$,

where $R$ is the ideal gas constant; $T$ is temperature; $M W_{o m}$ is the mean molecular weight of the absorbing medium; $f_{\text {om }}$ is the weight fraction of the total suspended particulate material that constitutes the absorbing om phase; $\zeta_{i}$ is the activity coefficient of compound $i$ in the particulate phase, generally assumed to be close to unity (Kamens et al., 1999) and $p_{L, i}^{0}$ is the subcooled vapour pressure of compound $i$ at temperature $T$.

The vapour pressure of a compound measures its ability to escape from the condensed phase, which depends on the strength of the intermolecular forces existing between the condensed molecules. The relatively weak dispersion forces (resulting from temporary dipoles formed in adjacent molecules) are the sole cohesive agent in liquid alkanes, which explains their high vapour pressures. In oxygenated compounds, cohesion is reinforced by the hydrogen bonds existing between the polar groups of the molecules (Poling et al., 2001). Due to the important role played by these hydrogen bonds, the vapour pressure of an oxygenated organic compound is strongly dependent on the number and type of oxygenated functionalities, as well as on the carbon structure (e.g. carbon number, nature and positions of the branchings) of the molecule.

The products of the oxidation of $\alpha$-pinene by $\mathrm{OH}$ (Peeters et al., 2001; Capouet et al., 2004) and $\mathrm{O}_{3}$ (Saunders et al., 2003) bear one or several oxygenated groups among them

Published by Copernicus GmbH on behalf of the European Geosciences Union. 
carbonyl, hydroxy, nitrate, hydroperoxy and carboxy functionalities. Experimental data are lacking for the thermodynamic properties of a large majority of these products. In this paper, we describe a semi empirical extrapolation method for predicting the vapour pressure of the $\alpha$-pinene oxidation products. Given their large number, this method is meant to be relatively simple and straightforward to apply. It is based on the so-called "group contribution" principles.

\section{Group contribution principles}

Group contribution methods attempt to correlate structural molecular properties (descriptors) with mathematical functions representing a chemical property of a molecule for a category of compounds by means of statistical methods. The descriptors are usually atom groups. Their "contributions" are obtained by fitting an adopted mathematical/physical function to a set of experimental data. These estimation methods are therefore essentially empirical. A group contribution method expresses the thermodynamic property of a chemical compound such as its vapour pressure as a function of a sum of contributions $\tau_{i}(T)$ of small groups of atoms $i$ constituting the molecule:

$p=f\left(\sum_{i} \tau_{i}(T)\right)$.

A large variety of group contribution methods have been designed in the past years, differing in their field of applicability and in the set of experimental data they are based on.

Jensen et al. (1981), Joback and Reid (1987), Tu (1994) and $\mathrm{Li}$ et al. (1994) proposed such methods for the prediction of a variety of thermodynamic properties (e.g. vapour pressure, critical temperature, critical pressure, boiling point) of organic compounds. These predictive methods are based on different data sets and provide estimations for specific or various classes of compounds including alkanes, alkenes, aromatics, halogenated hydrocarbons, oxygen-, sulfur- or nitrogen-containing monofunctional compounds. Other approaches have been proposed to estimate the vapour pressure of a component: e.g. Makar (2001) adopted an approach where the vapour pressures are directly estimated from polynomials, functions of the carbon number and temperature, defined for 39 structural classes. Myrdal and Yalkowsky (1997) proposed a method which requires the knowledge of the normal boiling point as well as structural information related to the molecule flexibility.

In recent years, the experimental identification of multifunctional compounds in secondary organic aerosols has strengthened the need for new prediction methods dedicated to these complex species. Marrero and Gani (2001) and Olsen and Nielsen (2001) developed methods which perform estimations at different levels. While the primary level describes a wide variety of simple, monofunctional groups, the higher levels treat multifunctional structures and allow to differentiate between isomers by considering, to some extent, the interactions among functionalities. Asher et al. (2002) developed a method based on the principles of UNIFAC (Universal Functional Group Activity Coefficients (Fredenslund et al., 1977)). It provides vapour pressure estimates of mono- and multifunctional oxygen-containing species using only 12 group contributions.

Vapor pressure estimates of monofunctional species by current methods are reasonably accurate. An evaluation of several methods performed by Asher et al. (2002) shows that the vapour pressures of volatile compounds having $\log _{10} p_{L, i}^{0} \geq-3$ at ambient temperature are predicted by current methods to within a factor 2 on average. For less volatile compounds (often multifunctional), i.e. $\log _{10} p_{L, i}^{0} \leq-5$, uncertainties are estimated to a factor 3 for the UNIFAC method and up to an order of magnitude for other methods. This explains the broad use of UNIFAC in SOA models (Griffin et al., 2005). The failure to provide more accurate predictions for low volatile compounds is related in part to experimental difficulties. Measurements of low vapour pressures are easily contaminated by impurities or biased by adsorption of the organic on the reactor walls. The literature reports experimental vapour pressure measurements for only about one hundred multifunctional compounds. The relative uncertainty of their measurements, when known, ranges from 25\% to 50\% (Hallquist et al., 1997; Bilde and Pandis, 2001; Bilde et al., 2003). Another important cause for the inaccuracy in the predictions for multifunctional compounds is the poorly quantified role of interactions between the chemical functionalities. Although they appear to have a large impact on the vapour pressure, their quantification remains difficult in part because of the scarcity of data for these compounds.

A major drawback of the methods described above is the absence of parameterization for chemical classes believed to play an important role in SOA formation (e.g. organic nitrates). The vapour pressure estimation method described in this work is intended to provide vapour pressure predictions for broad categories of $\alpha$-pinene degradation products including alcohols, carboxylic acids and carbonyls (classes which were considered by the methods cited above) as well as nitrates, peroxy acyl nitrates (PANs) and hydroperoxides (which were ignored by these methods).

\section{Method proposed in this work}

The literature sources for experimental data of liquid vapour pressure used in this study are listed in Table 1 (last column). The vapour pressures at $298 \mathrm{~K}$ for a selection of compounds are shown as a function of carbon number in Figs. 1 and 2. Both figures distinguish between linear (single-chained) compounds, denoted by the prefix " $\alpha-$ " or " $\alpha, \omega-$ ", and the other compounds, including cyclic species, alkyl substituted species and/or species with a functionality not positioned at one extremity of the molecule. The "tri-O-acids" (Table 1) 


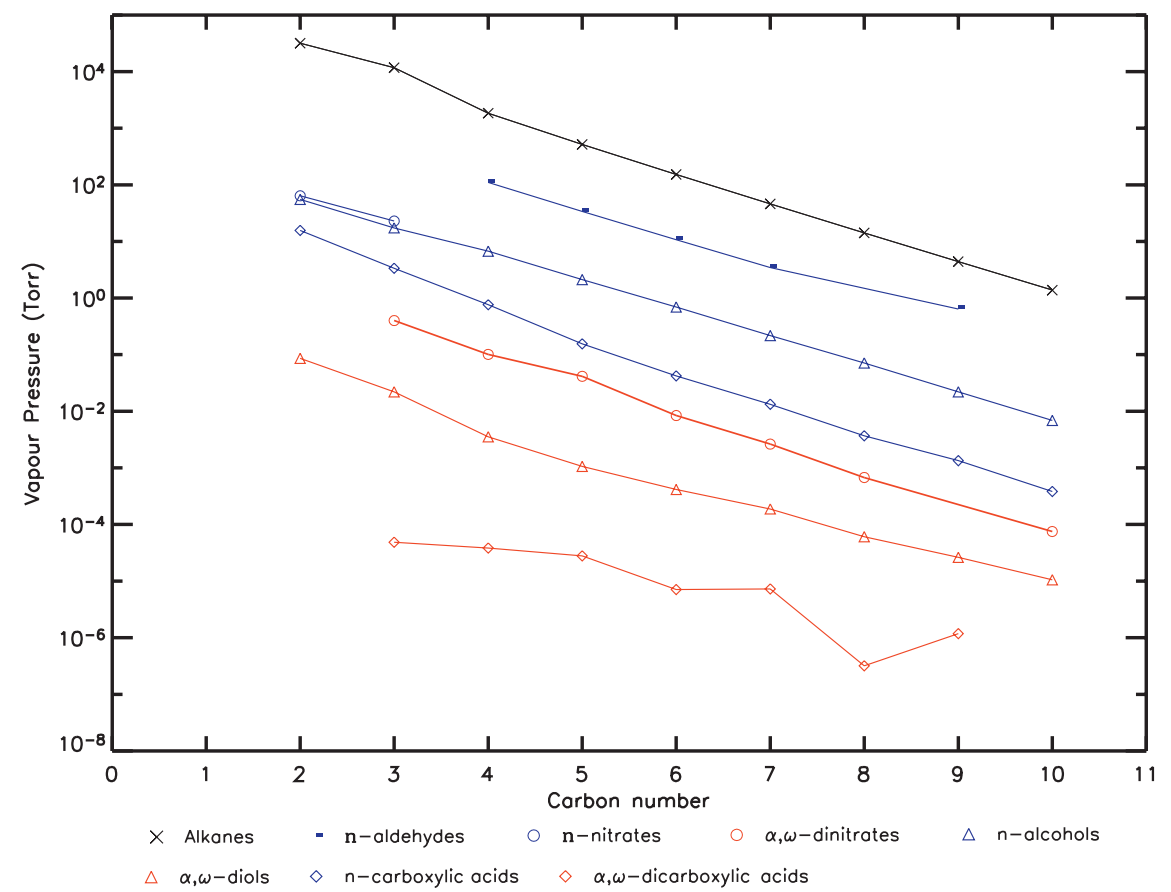

Fig. 1. Subcooled vapour pressures of linear monofunctional and difunctional compounds at $298 \mathrm{~K}$. Species prefixed by " $n-$ " or " $\alpha, \omega-$ " are of type " $\mathrm{CH}_{3}-\left(\mathrm{CH}_{2}\right)_{n}-\mathrm{X}$ " or " $\mathrm{X}-(\mathrm{CH} 2)_{\mathrm{n}}-\mathrm{X}$ ", respectively, with $\mathrm{X}$ being an oxygenated functionality.

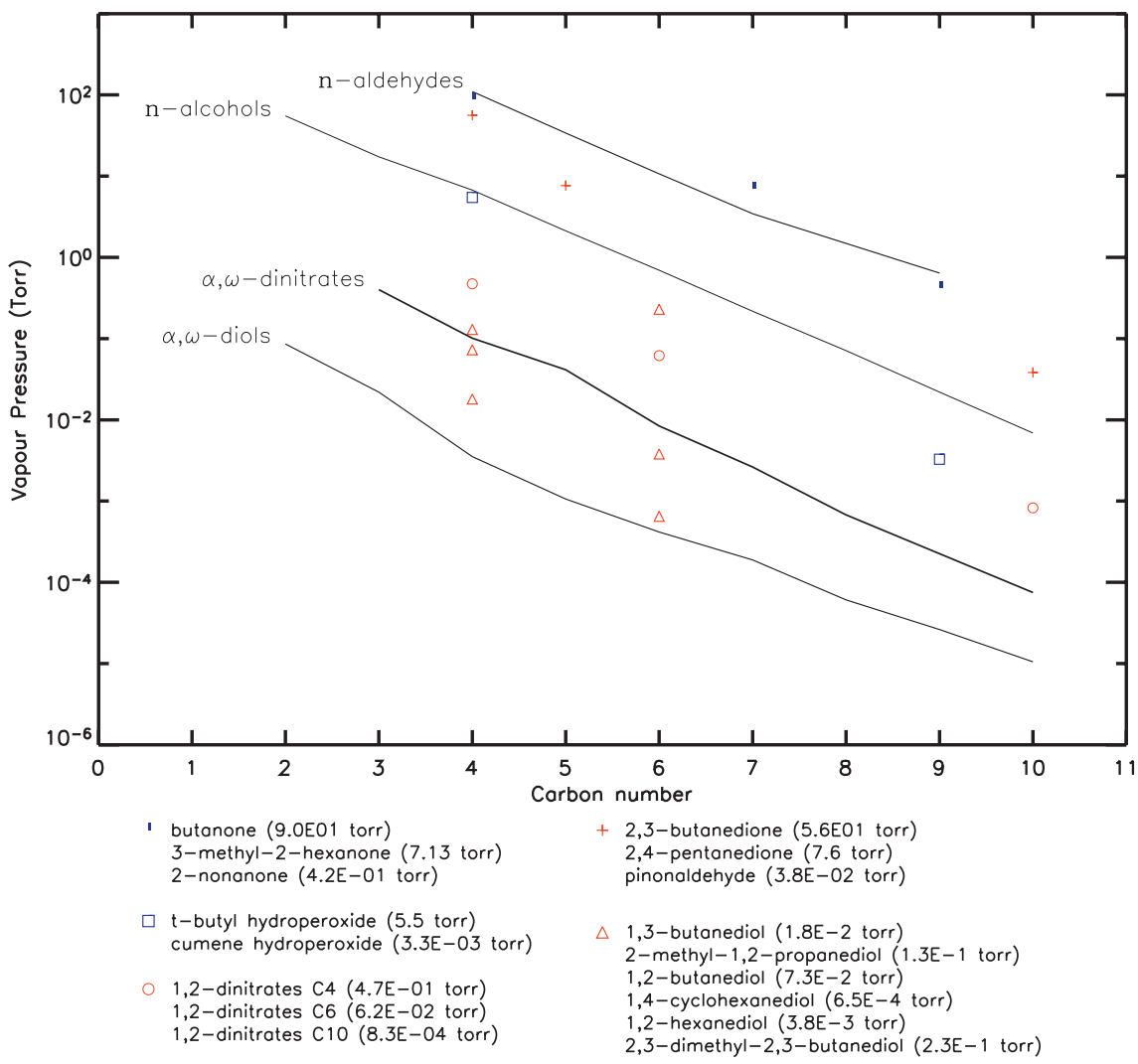

Fig. 2. Subcooled vapour pressures of a selection of monofunctional and difunctional compounds at $298 \mathrm{~K}$. Black curves indicating the vapour pressures of linear " $n-$ " and " $\alpha, \omega-$ ' compounds (see Fig. 1) are shown for comparison. 
class follows the definition by Makar (2001). This class represents three-oxygen-carboxylic acids, i.e., carboxylic acids with a carbonyl or hydroxy functionality.

The vapour pressure data for volatile compounds $\left(\log _{10} p_{L, i}^{0} \geq-3\right)$ are usually direct measurements performed at the temperatures of interest. However, the vapour pressures of less volatile compounds are often made at higher temperatures. The error caused by the extrapolations to ambient temperatures depends on the method used but can be larger than the experimental uncertainties. We have compared the vapour pressures data of diols provided by three sources. Yaws (1994) and Daubert and Danner (1989) interpolate the data using different modified equations of Antoine with five-parameters. ESDU (2001) provides data under the form of the Wagner equation:

$$
\begin{aligned}
\ln \left(p_{L}^{0}\right)= & \ln \left(P_{c}\right)+\left(a \times Q+b \times Q^{1.5}+c \times Q^{2.5}\right. \\
& \left.+d \times Q^{5}\right) /\left(T / T_{c}\right),
\end{aligned}
$$

with $Q=1-T / T_{c}$. $\mathrm{T}_{c}$ and $\mathrm{P}_{c}$ are the critical temperature and pressure, respectively. The parameters $\mathrm{a}, \mathrm{b}, \mathrm{c}, \mathrm{d}$ are determined by a constrained fit to the data. The comparison shows that in the temperature range of $290 \mathrm{~K}-320 \mathrm{~K}$, the interpolation methods lead to differences reaching a factor of 2 on average. The Wagner equation is believed to be more accurate than usual other fits because of its larger number of correlated parameters, and is particularly recommended for extrapolation to lower temperatures (Poling et al., 2001). The ESDU data have been therefore preferred in this work for the diols.

When the vapour pressure of low volatility compounds is measured at ambient temperatures, it may also be required to transform the vapour pressure data from the solid $\left(p_{s}^{0}\right)$ to the subcooled state. This conversion is obtained using the equation described in Prausnitz (1969):

$$
\begin{aligned}
\ln p_{L}^{0}= & \ln p_{s}^{0}-\frac{\Delta S_{\text {fus }}}{R}\left(1-T_{t} / T\right) \\
& -\frac{\Delta C_{p}}{R}\left(\frac{T_{t}-T}{T}\right)+\frac{\Delta C_{p}}{R} \ln \left(\frac{T_{t}}{T}\right),
\end{aligned}
$$

where $\mathrm{T}_{t}$ is the temperature of the triple point, $\Delta S_{\text {fus }}$ is the entropy of fusion and $\Delta C_{p}$ is the difference of heat capacity between the liquid and solid states. The subcooled vapour pressures of $\alpha, \omega$-dicarboxylic acids and $\mathrm{C}_{\geq 7} \alpha, \omega$-diols used in this study have been deduced using Eq. (4) on the basis of the measurements of their solid vapour pressures between 290 and $320 \mathrm{~K}$. The use of the normal melting point instead of the triple point introduces little difference, and the experimental uncertainty on the entropy change is at most $2 \%$ for these categories of compounds (NIST, 2004). Moreover, when $\mathrm{T}$ and $\mathrm{T}_{t}$ are not far apart as in the case of the diols, the two last terms tend to cancel each other and only the first term has to be considered. However, the melting points of the C3-C9 dicarboxylic acids are much higher (around $400 \mathrm{~K})$. The lack of experimental data for $\Delta C_{p}$ implies a larger uncertainty for $p_{L}^{0}$ in this case. If we assume $\Delta C_{p}$ to be $100 \mathrm{~J} \mathrm{~mol}^{-1} \mathrm{~K}^{-1}$ for the carboxylic acids on the basis of the data available from the NIST website, and assuming an experimental error of $50 \%$, Eq. (4) could overestimate the vapour pressures of dicarboxylic acids by a factor 3 on average. Bilde et al. (2003) have shown that the vapour pressures of solid C3-C9 $\alpha, \omega$-dicarboxylic acids depend strongly on the parity of the carbon number. The high stability of the crystal structure of even-number $\alpha, \omega$-dicarboxylic acids (resulting in lower vapour pressures) is believed to be due to their increased symmetry. This is confirmed by Rosenorn et al. (2003) who reported that the solid vapour pressures of methyl substituted dicarboxylic acids show no dependence on parity. The higher stability of even-number $\alpha, \omega$ dicarboxylic acids is not observed in the liquid state at temperatures higher than $400 \mathrm{~K}$. This behaviour is not expected in the subcooled liquid state either, although the vapour pressure of suberic acid (C8) is lower than azelaic acid (C9) at $298 \mathrm{~K}$ (Fig. 1). This anomaly is likely to be a result of the large uncertainties on the subcooled vapour pressures.

The vapour pressure data for the dinitrates constitute direct measurements. Their experimental uncertainties are not known.

Note that all species listed in Table 1 are either mono- or difunctional. Based on the group contribution principles, and in absence of data for species bearing more than two functionalities, we assume the method to be applicable to all multifunctional species. Figure 1 shows that there is a roughly linear relationship between the logarithm of the vapour pressure and the carbon number, with an approximately constant slope for all classes, especially for $n \geq 4$. Figure 2 also shows that the vapour pressures of different isomers of dinitrates and diols sometimes cover several orders of magnitude, with the $\alpha, \omega$-compounds presenting the lowest values. Our prediction method aims at reproducing to some extent the differences in vapour pressure between different isomers.

The proposed method to estimate the vapour pressure of a compound $i$ at temperature $T$ has the following form :

$$
\log _{10} p_{L, i}^{0}(T)=\log _{10} p_{L, h c}^{0}(T)+\sum_{k}^{n} v_{k, i} \tau_{k}(T) .
$$

Here $p_{L, h c}^{0}(T)$ is the vapour pressure of the alkane "parent" $h c$, where all oxygenated functionalities in compound $i$ are replaced by hydrogen atoms (e.g. - $\mathrm{CH}(\mathrm{OH})$ - is replaced by $-\mathrm{CH}_{2}-$, etc), $v_{k, i}$ is the number of oxygenated functionalities of type $k$ in the compound $i, n$ is the number of defined types of oxygenated functionalities, and $\tau_{k}$ are the group contribution parameters. The first pressure term $\left(p_{L, h c}^{0}(T)\right)$ is obtained from experimental measurements for alkane compounds available in the literature. When no experimental value of the vapour pressure for the parent compound can be found, the group contribution method of Marrero and Gani (2001) is used to calculate the boiling point, the critical temperature and the critical pressure of the compound $h c . \quad \mathrm{p}_{L, h c}^{0}(T)$ is then obtained using the Lee and 
Table 1. Literature data used in this work, and standard error (as defined by Eq. 7) between the experimental and estimated vapour pressures, using the method developed in this work and using UNIFAC.

\begin{tabular}{|c|c|c|c|c|c|}
\hline Class of compounds & $\begin{array}{c}\sigma(298 \mathrm{~K}) \\
\text { This work }\end{array}$ & $\begin{array}{l}\sigma(298 \mathrm{~K}) \\
\text { UNIFAC }\end{array}$ & $\begin{array}{c}\sigma(320 \mathrm{~K}) \\
\text { This work }\end{array}$ & $\begin{array}{l}\sigma(320 \mathrm{~K}) \\
\text { UNIFAC }\end{array}$ & Sources \\
\hline Monocarbonyls & 0.21 & 0.36 & 0.16 & 0.29 & Lide (2001), ESDU (2001) \\
\hline Dicarbonyls & 0.26 & 0.56 & 0.15 & 0.65 & $\begin{array}{l}\text { HSDB (2004), Lide (2001), } \\
\text { Hallquist et al. (1997) }\end{array}$ \\
\hline Prim. ${ }^{\mathrm{d}}$ mononitrates & 0.33 & $-b$ & 0.22 & $-b$ & Lide $(2001)$ \\
\hline Prim. ${ }^{\mathrm{d}} n$-monoalcohols & 0.34 & 0.21 & 0.34 & 0.18 & Poling et al. (2001) \\
\hline Sec. ${ }^{\mathrm{d}}$ monoalcohols & 0.29 & 0.29 & 0.29 & 0.24 & Poling et al. (2001) \\
\hline Tert. $^{\mathrm{d}}$ monoalcohols & 0.12 & 0.27 & 0.06 & 0.27 & Poling et al. (2001) \\
\hline PAN-like compounds & $-{ }^{\mathrm{a}}$ & $-{ }^{\mathrm{b}}$ & $-{ }^{\mathrm{a}}$ & $-\mathrm{b}$ & Bruckmann and Willner (1983) \\
\hline Monohydroperoxides & 0.21 & $-b$ & $-^{\mathrm{a}}$ & $-b$ & Lide (2001), HSDB (2004) \\
\hline$(\text { prim. })^{\mathrm{d}} \alpha, \omega$-dinitrates & 0.11 & $-\mathrm{b}$ & $-^{\mathrm{c}}$ & $-\mathrm{b}$ & Fischer and Ballschmiter (1998) \\
\hline 1,2-dinitrates & 0.35 & $-b$ & $-^{\mathrm{c}}$ & $-\mathrm{b}$ & Fischer and Ballschmiter (1998) \\
\hline Sec. ${ }^{\mathrm{d}}$ dinitrates & 0.11 & $-b$ & $-^{\mathrm{c}}$ & $-b$ & Fischer and Ballschmiter (1998) \\
\hline (prim. $)^{\mathrm{d}} \alpha, \omega$-diols & 0.21 & 0.40 & 0.23 & 0.31 & ESDU (2001) \\
\hline Sec. ${ }^{\mathrm{d}}$ diols & 0.20 & 0.26 & 0.15 & 0.22 & ESDU (2001) \\
\hline Tert. $^{\mathrm{d}}$ diols & 0.14 & 0.89 & 0.13 & 0.78 & ESDU (2001) \\
\hline Other ${ }^{\mathrm{e}}$ diols & 0.28 & 0.38 & 0.29 & 0.43 & ESDU (2001) \\
\hline$n$-carboxylic acid & 0.27 & 0.11 & 0.04 & 0.11 & Poling et al. (2001) \\
\hline$\alpha, \omega$-dicarboxylic acid & 0.26 & 0.65 & 0.45 & 0.48 & Bilde et al. (2003) \\
\hline Hydroxy ketones & 0.43 & 0.58 & 0.34 & 0.50 & Lide (2001), Asher et al. (2002) \\
\hline Tri-O-acids ${ }^{f}$ & 0.42 & 0.50 & 0.61 & 0.60 & HSDB (2004), ESDU (2001) \\
\hline
\end{tabular}

${ }^{a}$ Only one experimental value. ${ }^{b}$ Not parameterized. ${ }^{c}$ No experimental data. ${ }^{d}$ Refers to the degree of substitution of the carbon(s) to which the functionality(ies) is(are) attached. Read "prim." as "primary", "sec." as "secondary", and "tert." as "tertiary". e The carbons bearing the functionalities have different degrees of substitutions. ${ }^{\mathrm{f}}$ Acid compounds with a carbonyl or hydroxy functionality.

Kesler formulation, function of these properties (Poling et al., 2001). The choice of the method of Marrero and Gani (2001) is motivated by its good performance for alkanes. A comparison study by these authors shows that their method performs better than the Joback and Reid (1987) method which is commonly used for the prediction of these thermodynamic parameters. We estimate that the error on $p_{L, h c}^{0}$ predicted using Marrero and Gani (2001) does not exceed 50\%, even in the case of the most complex structures of VOC.

Table 2 lists the temperature dependent contributions optimized in this work. Note that the group contributions for the nitrate and hydroxy functionalities depend on the degree of substitution of the carbon bearing the functionality (Fig. 3). The importance of this distinction can be illustrated by the observed lower vapour pressures of 1,6hexanediol and 1,2-butanediol, compared to their substituted isomers 2,3-dimethyl-2,3-butanediol and 2-methyl-1,2propanediol (Fig. 2). Only a minor part of this difference is related to the weaker dispersion forces existing in substituted hydrocarbons, as shown by the small difference $(30 \%)$ observed between the vapour pressures of the corresponding alkane isomers. The rest can be attributed to the interactions produced by the hydroxy functionalities. Their strength de- pends on the location of the chemical functionalities and the distance between each other in the molecules. This relatively minor influence of the dispersion forces explains the smaller error expected in the prediction of $p_{L, h c}^{0}(T)$ compared to the second term of Eq. (5) representing the influence of the functionalities. The effect of distance between functionalities has been investigated by Knauth and Sabbah (1990a,b,c). They have shown that, when the hydroxy functionalities are positioned close to each other in linear diols, intramolecular hydrogen bonds between the hydroxy functionalities are favored, resulting in less intermolecular cohesion and therefore in higher vapour pressures. Parameterizing both effects (presence of substitutions and distance between functionalities) simultaneously would require more data than is currently available. Our choice to take into account the effect of alkyl substitutions on the $\alpha$ carbon of the functionalities is motivated by the large number of substitutions in the $\alpha$ pinene oxidation products. Furthermore, this approach allows to include also some influence of the distance between the functionalities, since this distance is usually larger in primary diols and dinitrates from the data set than in their secondary isomers. An exception to this rule is provided by the case of the para-diols and para-dinitrates cyclic compounds. 


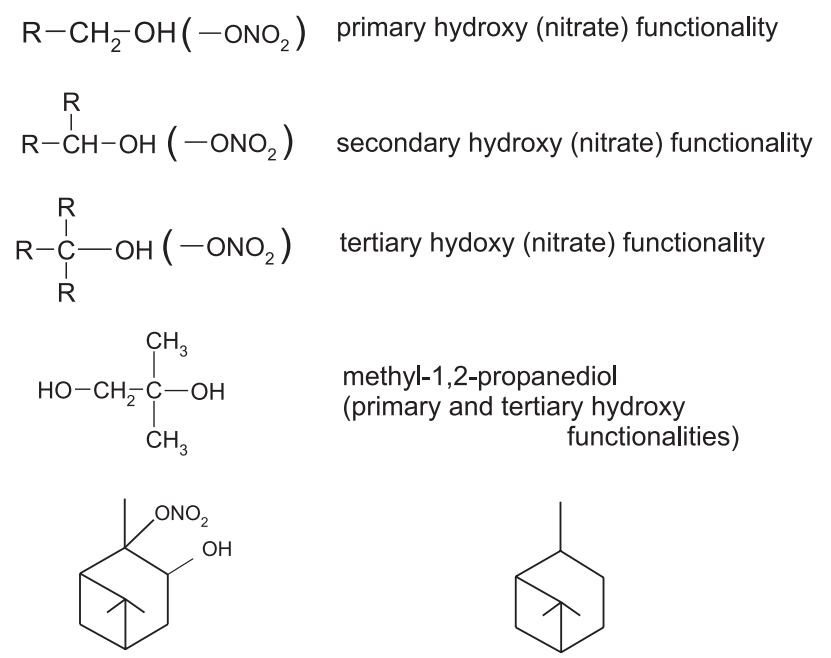

APINANO3

(tertiary nitrate and secondary hydroxy functionalities)

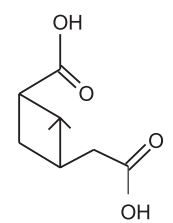

Pinic acid (two carboxy functionalities) parent compound of APINANO3

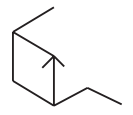

parent compound of pinic acid

Fig. 3. (a) Examples illustrating the degree of substitution of the hydroxy and nitrate functionalities as defined in this work. (b) Structure of APINANO3 and pinic acid with their respective alkane parent.

As for the linear diols, the effect of intramolecular interactions between two hydroxy groups can be seen in the vapour pressure data for cyclic diols and dinitrates. For example, the vapour pressure of cyclohexanediol isomers is seen to increase when the distance between the hydroxy groups decreases. 1,4-cyclohexanediol and 1,6-hexanediol are found to have similar vapour pressures, reflecting the fact that the hydroxy groups are situated at the respective opposites of the carbon structure in both molecules. Therefore, although the hydroxy groups of 1,4-cyclohexanediol are, strictly speaking, secondary, they are considered as primary in our parameterization of group contributions. Note that, in absence of vapour pressure data for tertiary and secondary (di)nitrates at different temperatures, the temperature dependence of their contributions is derived from the primary dinitrate contribution.

Since linear monoaldehydes and monoketones of same carbon number show very close vapour pressures, both functionalities are treated using a single contribution parameter $\tau_{\text {carb}}$. The linear dicarboxylic acids of even carbon number

are not taken into account in the determination of the carboxy contribution, since their symmetric structure (resulting in abnormally low vapour pressures) is not characteristic of the $\alpha$-pinene oxidation products. Vapor pressure data are scant for the hydroperoxides and peroxy acyl nitrates (PANs). The contributions shown in Table 2 for these classes are based on data for only three monofunctional hydroperoxides and one peroxy acyl nitrate (peroxy acetyl nitrate).

The principles of our prediction method are illustrated by the two following examples. In both cases, the Marrero and Gani (2001) method combined with the Lee and Kesler equation is used to predict the vapour pressure of the alkane parent (Fig. 3). Consider first APINANO3, a hydroxy nitrate produced from the oxidation of $\alpha$-pinene by OH (Saunders et al., 2003). Given the presence of a tertiary nitrate and a secondary hydroxy functionality in APINANO3, its vapour pressure at $298 \mathrm{~K}$ is estimated as:

$$
\begin{array}{ll}
\log _{10} p_{L, h c}^{0} & =0.4232 \\
-1 \times \tau_{\mathrm{ONO} 2 \mathrm{t}} & -1.2793 \\
-1 \times \tau_{\mathrm{OHs}} & -2.0374 \\
\hline \log _{10} p_{L, \text { APINANO3 }}^{0} & =-2.8935
\end{array}
$$

The second example is provided by pinic acid, a low volatility product formed in the ozonolysis of $\alpha$-pinene (Saunders et al., 2003). The vapour pressure of pinic acid at $320 \mathrm{~K}$ is estimated as:

$$
\begin{array}{ll}
\log _{10} p_{L, h c}^{0} & =1.6135 \\
-2 \times \tau_{\mathrm{COOH}} & -6.1732 \\
\hline \log _{10} p_{L, \text { pinic acid }}^{0} & =-4.5597
\end{array}
$$

\section{Minimization and comparison with the UNIFAC method}

The parameters $\tau_{k}$ are determined by the minimization of a cost function $J$ defined as

$J=\frac{1}{2} \sum_{i}^{N} \frac{\left(\log _{10} p_{L, i}^{0, \text { mod }}-\log _{10} p_{L, i}^{0, \exp }\right)^{2}}{\left(E_{i}\right)^{2}}$.

The cost function $J$ measures the bias between the model and the entire set of available data ( $N$ species) listed in Table 1 . Being a quadratic function of $\tau_{k}$, its minimization is straightforward. The minimization has been performed at two temperatures $(298 \mathrm{~K}$ and $320 \mathrm{~K}) . E_{i}$ represents the assumed error associated to the data of compound $i$. It is primarily related to the observational uncertainty, but also to the expected ability of the model to reproduce these data. The uncertainty on $\log _{10} p_{L, i}^{0, \exp }(T)$ range from 0.1 to 0.5 , depending on the volatility of the compounds. Note that, as discussed previously, the data for the diols and dicarboxylic acids are not direct measurements. However, they 
Table 2. Optimized group contributions $\left(\tau_{k}\right)$, as functions of the temperature $(\mathrm{T})$. The last column reports the number of species for which experimental data are available in each class.

\begin{tabular}{llll}
\hline Class of compounds & Abr. & Contribution & Nb. of Species \\
\hline Carbonyl & $\tau_{\text {carb }}$ & $-0.8937+0.0039 \times(\mathrm{T}-298)$ & 16 \\
Primary $^{\mathrm{a}}$ nitrate & $\tau_{\mathrm{ONO} 2 \mathrm{p}}$ & $-2.0897+0.0063 \times(\mathrm{T}-298)$ & 16 \\
Secondary $^{\mathrm{a}}$ nitrate & $\tau_{\mathrm{ONO} 2 \mathrm{~s}}$ & $-1.6711+0.0063 \times(\mathrm{T}-298)$ & 0 \\
Tertiary $^{\mathrm{a}}$ nitrate & $\tau_{\mathrm{ONO} 2 \mathrm{t}}$ & $-1.2793+0.0063 \times(\mathrm{T}-298)$ & 3 \\
Hydroperoxy $_{\text {Primary }}^{\mathrm{a}}$ hydroxy & $\tau_{\mathrm{OOH}}$ & $-2.9942+0.0361 \times(\mathrm{T}-298)$ & 28 \\
Secondary $^{\mathrm{a}}$ hydroxy & $\tau_{\mathrm{OHp}}$ & $-2.6738+0.0171 \times(\mathrm{T}-298)$ & 22 \\
Tertiary ${ }^{\mathrm{a}}$ hydroxy & $\tau_{\mathrm{OHs}}$ & $-2.0374+0.0124 \times(\mathrm{T}-298)$ & 1 \\
Carboxy & $\tau_{\mathrm{OHt}}$ & $-1.4418+0.0103 \times(\mathrm{T}-298)$ & 13 \\
PANs & $\tau_{\mathrm{COOH}}$ & $-3.2516+0.0075 \times(\mathrm{T}-298)$ & 1 \\
\hline
\end{tabular}

${ }^{a}$ Refers to the degree of substitution of the carbon(s) to which the functionality(ies) is(are) attached.

are the best measurement-based data available. Since the less volatile multifunctional compounds are expected to contribute most to organic aerosol formation, the errors $E_{i}$ are adjusted in order to favour the ability of the method to reproduce their vapour pressures: $E_{\text {mono }}=0.5$ for the monofunctional compounds and $E_{\text {multi }}=0.3$ for the multifunctional compounds. Using these values, we obtain after minimization, $J(298) / N=0.43$ and $J(320) / N=0.45$ for both categories, i.e., the modeled vapour pressures fall well within the range of uncertainty adopted for the observations. The vapour pressures of the alkane parents "hc" of the data set used for the derivation of the parameters " $\tau_{k}(T)$ " are experimental measurements except in the case of pinonaldehyde and caronaldehyde. The vapour pressures of the alkane parents for these two compounds were estimated using the Marrero \& Gani/Lee \& Kesler method.

The vapour pressure predictions can be approximated by assuming a linear dependence of $\tau_{k}(T)$ with $T$, deduced from their values at 298 and $320 \mathrm{~K}$. Comparisons between predictions and experimental data have been conducted at 290 and $310 \mathrm{~K}$. They show that the prediction uncertainty at $310 \mathrm{~K}$ is close to the average of their values at $298 \mathrm{~K}$ and $320 \mathrm{~K}$. Predictions at $290 \mathrm{~K}$ are found to be of similar uncertainty as those at $298 \mathrm{~K}$. Meaningful comparisons at lower temperatures are difficult due to the lack of experimental data for multifunctional compounds at low temperatures.

The experimental data of vapour pressures are compared with the predictions using this method and using UNIFAC (Asher et al., 2002) in Figs. 5 and 6, respectively. Table 1 shows the standard prediction error for both methods and for each compound class calculated as in UNIFAC as

$\sigma_{i}(T)=\frac{\sum_{i}^{n}\left|\log _{10} p_{L, i}^{0, \exp }(T)-\log _{10} p_{L, i}^{0, \bmod }(T)\right|}{n}$,

where $n$ is the number of compounds in class $i$. The vapour pressures predicted by both methods for a selection of compounds are compared with the experimental data in Fig. 4.
Our method performs as well as UNIFAC for monoalcohols with a slight improvement for substituted compounds. We obtain better predictions for the diols, giving support to the parameterization used to distinguish between isomers. However, in view of the relatively large uncertainties in the data, the improvement might not be conclusive, except for very substituted diols (e.g. 2,3-dimethyl-2,3-butanediol in Fig. 4). The poor performance of UNIFAC for dicarbonyls is due to its large error $(\sigma \sim 0.8)$ for pinonaldehyde, pentanedione and butanedione. The values of the averaged standard error for alcohols (including monoalcohols and diols) are 0.22 and 0.37 for our method and for UNIFAC, respectively.

The validity of a group contribution method depends on the number and diversity of data it is based on. A drawback of the vapour pressure data set used here is the scarceness of information for heterofunctional species (compounds bearing different oxygenated functionalities): vapour pressure data are known for only 4 hydroxy ketones and 2 tri$\mathrm{O}$-acids species. Both our method and UNIFAC provide fairly good predictions for hydroxy ketones, with $\sigma \lesssim 0.5$ (Table 1). However, they both fail to predict the vapour pressures of tri-O-acids. For example, our $p_{L, i}^{0}$ prediction for pyruvic acid $\left(\mathrm{CH}_{3} \mathrm{COCOOH}\right)$ is excellent at both temperatures (Fig. 4), but a bias of one order of magnitude is obtained in the case of levulinic acid $\left(\mathrm{CH}_{3} \mathrm{CO}\left(\mathrm{CH}_{2}\right)_{2} \mathrm{COOH}\right)$ at $320 \mathrm{~K}$. A good agreement with the experimental data is obtained with our method for 2-hydroxy propanoic acid at 298 K. Tobias et al. (2000) deduced the subcooled vapour pressure of $\alpha$-hydroxytridecyl hydroperoxide on the basis of temperature-programmed thermal desorption (TPTD) analysis $\left(3 \times 10^{-9 \pm 1}\right.$ torr $)$. The value predicted by our method for this hydroxy hydroperoxide is two orders of magnitude higher (see Fig. 5). This difference being much larger than the standard prediction errors calculated for the compounds containing hydroperoxy and/or hydroxy functionality(ies) (monohydroperoxides, monoalcohols, diols, hydroxy ketones, hydroxy carboxylic acids), this compound 


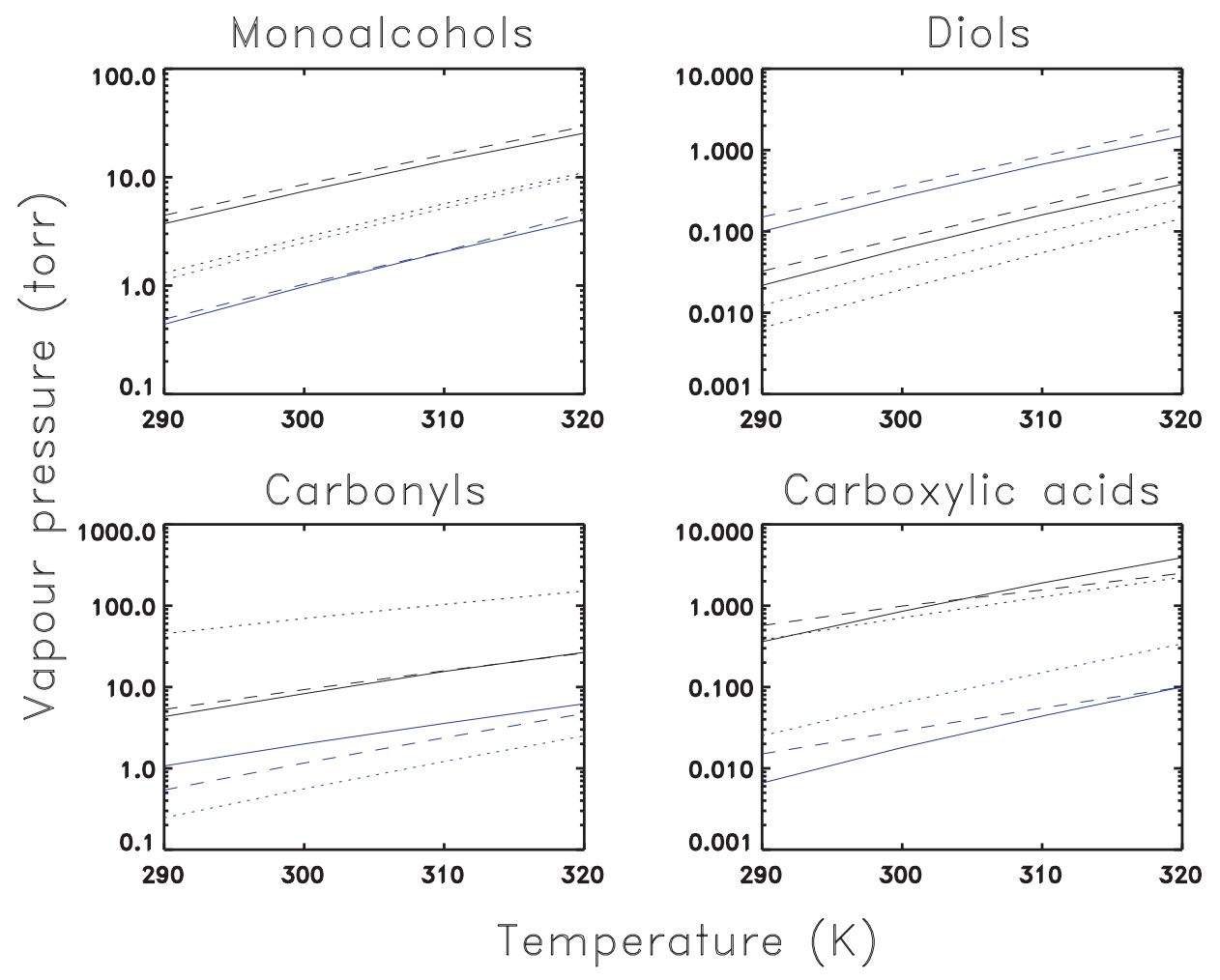

Fig. 4. Temperature dependence of the vapour pressure for a selection of compounds reported by experimental measurements (solid lines), estimated by UNIFAC (dotted lines) and by the method developed in this work (dashed lines). Represented in black and in blue, respectively: Monoalcohols:2-methyl-2-pentanol and cyclohexanol; diols: 2-methyl-2,4-pentanediol and 2,3-dimethyl-2,3-butanediol; carbonyls: pentadione and 4-hydroxy-4-methyl-2-pentanone; carboxylic acids: pyruvic acid and cyclohexanoic acid.

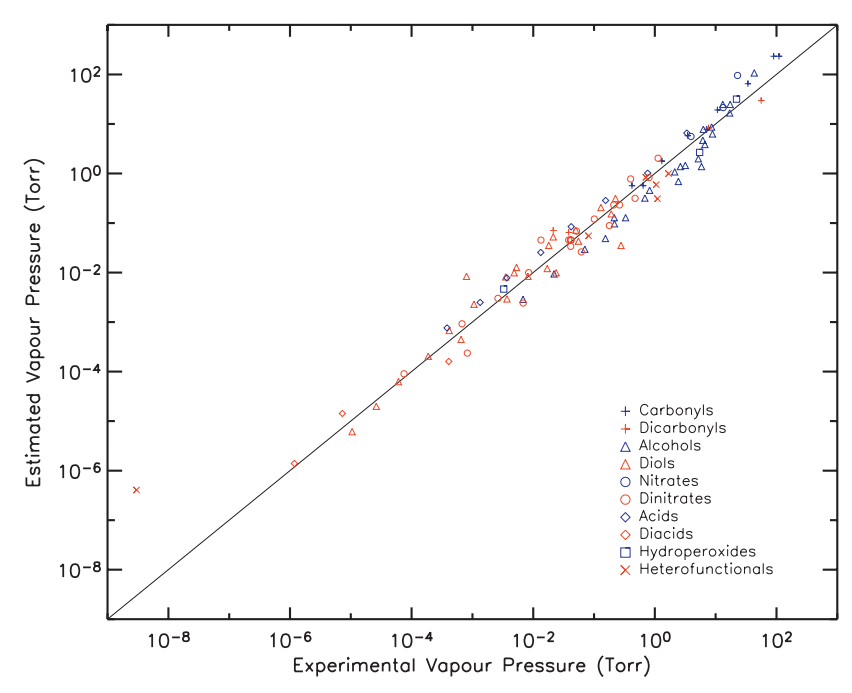

Fig. 5. Subcooled vapor pressures estimated using the prediction method developed in this work against the experimental vapour pressures (sources in Table 1). Monofunctional and difunctional compounds are represented in blue and red, respectively.

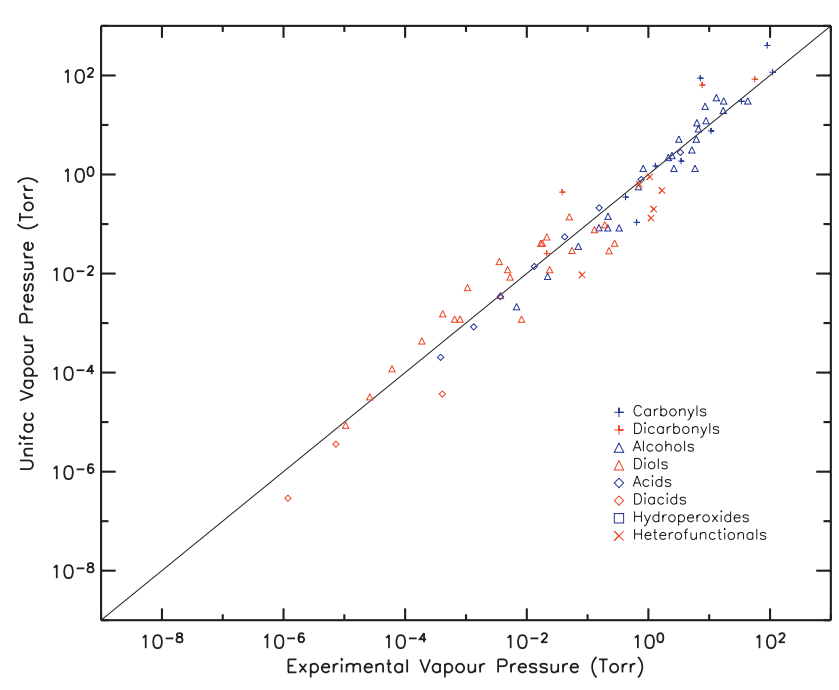

Fig. 6. Subcooled vapor pressures estimated using UNIFAC against the experimental vapour pressures (sources in Table 1). Monofunctional and difunctional compounds are represented in blue and red, respectively. 
was omitted from the dataset used for the minimization. The low measured vapour pressure is surprising since, as noted previously, the closeness of functionalities tends to increase the vapour pressure. Experimental artefacts are not excluded. Further studies are required to better quantify the interactions between functionalities, as well as the role of molecular structure (e.g. presence of substitutions, of cycles) in multifunctional compounds in order to provide satisfactory predictions for the products originating from the oxidation of biogenic hydrocarbons.

Figure 5 shows that our calculated $\log _{10} p_{L, i}^{0}$ for monoalcohols are underpredicted by $\sigma=0.3$, while the predictions for the monocarboxylic acids are roughly overpredicted by $\sigma=0.2$. These systematic biases for monofunctional classes are related to the oversimplified functional form adopted for parameterizing the vapour pressures. These biases are of little consequence in the context of secondary organic aerosol modeling, however, since the least volatile multifunctional compounds are expected to contribute most to the aerosol mass.

\section{Vapor pressure estimations for $\alpha$-pinene oxidation products}

Figure 7 shows the variation with temperature of the vapour pressure of several important $\alpha$-pinene degradation products (see MCM 3 (Saunders et al., 2003) for identification of the compound), as estimated using the method developed in this work. It is also compared with vapour pressures estimates derived from previous studies, when available.

Bilde and Pandis (2001) measured the melting point and the evaporation rate of solid pinic acid and deduced its vapour pressure over the range $290-323 \mathrm{~K}$. The fusion entropy change $\left(\Delta S_{\text {fus }}\left(T_{m}\right)\right)$ necessary to deduce the corresponding subcooled vapour pressure is unknown for pinic acid. However, NIST (2004) reported the values for $\Delta S_{\text {fus }}\left(T_{m}\right)$ for azelaic acid $\left(86 \mathrm{~J} \mathrm{~mol}^{-1} \mathrm{~K}^{-1}\right)$ and nonanoic acid $\left(69 \mathrm{~J} \mathrm{~mol}^{-1} \mathrm{~K}^{-1}\right)$. Given the presence of two carboxylic functionalities and the non-linear carbon structure of pinic acid, we can assume that $\Delta S_{\text {fus }}\left(T_{m}\right)$ of pinic acid lies between these two values. Introducing their average in Eq. (4), we obtain an estimation of the dependence of the subcooled vapour pressure with temperature for this compound (solid line in Fig. 7). The overall uncertainty due to experimental errors and to the conversion into the subcooled state is estimated to a factor 2. Both our method and UNIFAC calculate values which are about a factor of 3 higher than this estimation over the range of ambient temperatures. The agreement is fair given the uncertainty of $50 \%$ on the measurements performed by Bilde and Pandis. Jenkin (2004) and Yu et al. (1999) estimated the vapour pressure of the $\alpha$-pinene oxidation products based on a modified form of the ClausiusClapeyron equation (Scharzenbach et al., 1993). This equation is function of the boiling point and the molar heat (or entropy) of vaporization. The vapour pressure calculated by Jenkin for pinic acid at $298 \mathrm{~K}$ using this equation is about two orders of magnitude higher than the experimentally deduced value at that temperature. This discrepancy could originate from the group contribution method of Joback and Reid (1987) used to estimate the boiling point of pinic acid. This method appears unappropriate for predicting thermodynamical properties of dicarboxylic acids. For example, Jenkin estimates the melting point of pinic acid to be $542 \mathrm{~K}$ using this method, $200 \mathrm{~K}$ above the experimental value (Bilde and Pandis, 2001) .

It is important to note that carboxylic acids are known to form dimers in the gas phase (Singleton et al., 1987; Orlando and Tyndall, 2003). For example, at $298 \mathrm{~K}$, the vapour pressure of the dimer represents about $90 \%$ of the total vapour pressure of acetic acid in equilibrium with its pure liquid phase (Orlando and Tyndall, 2003). Recently, Kuckelmann et al. (2000) observed pinic acid dimers as well as adducts of pinonic acid and pinic acid. The dimers of pinic acid were observed to be abundant. The stability of these dicarboxylic acid dimers can be expected to be high, due to the strong hydrogen bonds formed between the carboxy groups of the monomers. As in the case of acetic acid, we can expect the partial vapour pressure of the dimer form to contribute significantly to the total vapour pressure for many (di)carboxylic acids, and in particular for pinic acid. It follows that the vapour pressure of the dimer should be close to the experimental total (dimer+monomer) vapour pressure for these compounds. In the pinic acid/pinonic acid adduct, the carbonyl site in one carboxy group in pinic acid is not H-bonded and therefore able to form an hydrogen bond with another component (Fig. 8). Therefore, the vapour pressure of the pinic-pinonic acid adduct should then be on the same order, or even lower, than the vapour pressure of the pinic acid dimer $\left(\sim 1 \times 10^{-6}\right.$ torr $)$ at ambient temperature.

The vapour pressure estimated by our method for pinonaldehyde agrees well with the measurements of Hallquist et al. (1997) (experimental uncertainty: 25\%). Bilde and Pandis (2001) measured the vapour pressure of pinonic acid to be $\sim 5.3 \times 10^{-7}$ torr at $296 \mathrm{~K}$, but they did not consider this value as reliable, due to experimental problems. UNIFAC predicts vapour pressure values which are an order of magnitude higher than our estimations for these two compounds.

Bonn et al. (2004) is, to our knowledge, the only previous study providing vapour pressure estimations for hydroperoxides, organic nitrates and PANs generated by the oxidation of $\alpha$-pinene. They provided temperature dependent estimations for the vapour pressure of APINANO3 (Fig. 7). Their estimation uses the group contribution relationship established by Nielsen et al. (1998) which relates the vapour pressure of organic nitrates to their number of carbons and their number of carbonyl, nitrate and hydroxy functionalities. The optimization of the contributions is based on a data set including hydrocarbons, alcohols, diols, carbonyls, alkyl nitrates, small hydroxy nitrates and dinitrates of different structures. The 

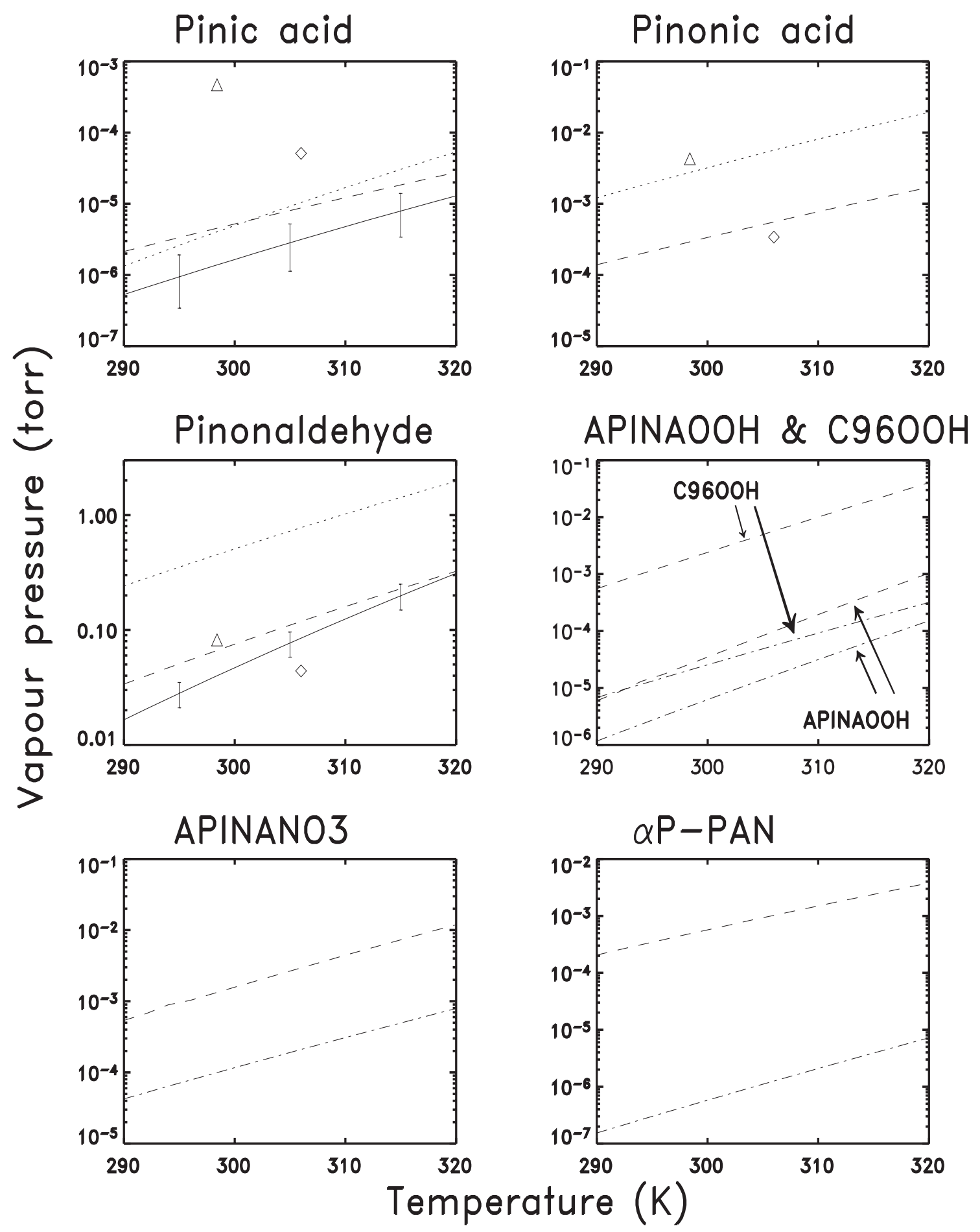

Fig. 7. Vapor pressure of individual compounds estimated from the measurements (solid lines with error bars), the method developed in this work (dashed), the UNIFAC method Asher et al. (2002) (dotted), Bonn et al. (2004) (dash dotted), Jenkin (2004) at 298 K (triangles) and Yu et al. (1999) at $306 \mathrm{~K}$ (diamonds). 
influence of the carbon structure on vapour pressure is not taken into account. For $\mathrm{C}_{10}$ hydroxy nitrates, this method calculates a vapour pressure of $2 \times 10^{-4}$ torr at ambient temperature. The vapour pressures we calculate for such compounds, assuming a moderately substituted carbon structure, are $\sim 5 \times 10^{-5}$ torr (primary functionalities), $\sim 5 \times 10^{-4}$ torr (secondary functionalities) and $\sim 7 \times 10^{-3}$ torr (tertiary functionalities). The value of Nielsen et al. falls therefore well in our range. Our higher values calculated for APINANO3 (Fig. 7) result from the tertiary degree of its nitrate functionality and its branched carbon structure. The vapour pressure relationship proposed by Bonn et al. for $\alpha$-pinonyl peroxy nitrate ( $\alpha \mathrm{P}$-PAN), a product from the oxidation of pinonaldehyde by $\mathrm{OH}$, is also partly based on the parameterization of Nielsen et al. (1998) for nitrate compounds.

As for the nitrates, our vapour pressure estimates for the hydroperoxides APINAOOH and $\mathrm{C} 96 \mathrm{OOH}$ are higher than in Bonn et al.. Bonn et al. based their estimations on UNIFAC and on vapour pressure data for small hydroperoxides and for the $\mathrm{C}_{13}$ hydroxy hydroperoxide measured by Tobias et al. (2000). The exceptionally low vapour pressure of the latter compound has not been taken into account in our derivation of the hydroperoxy contribution, which might explain the discrepancy between our method and Bonn et al. estimations. As in Bonn et al., however, we predict a lower vapour pressure for APINAOOH than for $\mathrm{C} 96 \mathrm{OOH}$, due to its hydroxy functionality and its higher carbon number. Taking into account the Tobias et al. data in the minimization would increase the magnitude of the hydroperoxy contribution $\left(\tau_{\mathrm{OOH}}\right)$, with -3.5231 at $298 \mathrm{~K}$ (instead of -2.9942 , cfr. Table 2). The impact on $\tau_{\mathrm{OHs}}$ is negligible due to the large amount of data used to constrain this functionality. The vapour pressures of APINAOOH predicted using this alternative value of $\tau_{\mathrm{OOH}}$ coincide with those determined by Bonn et al.. However, the standard error $\sigma$ for the hydroperoxide class becomes very large, increasing from 0.2 (Table 1) to 1.3 .

\section{Conclusions}

A group contribution method has been proposed to predict the vapour pressure of the products generated by the oxidation of $\alpha$-pinene. Parameterizations are derived for the influence of the carbonyl, hydroxy, nitrate, peroxy acyl nitrate, carboxy and hydroperoxy functionalities. The impact of alkyl substitutions is also parameterized for alcohols and nitrates. The predicted vapour pressures are within a factor 2-3 of the experimental values for multifunctional compounds. Further experimental studies are required to investigate $1 /$ the effect of the substitutions, 2/ the effect of the distance between functionalities on the vapour pressure and 3 / the vapour pressure of heterofunctional compounds.

Our findings support the hypothesis that, among the $\alpha$ pinene products identified to date, dicarboxylic acids and
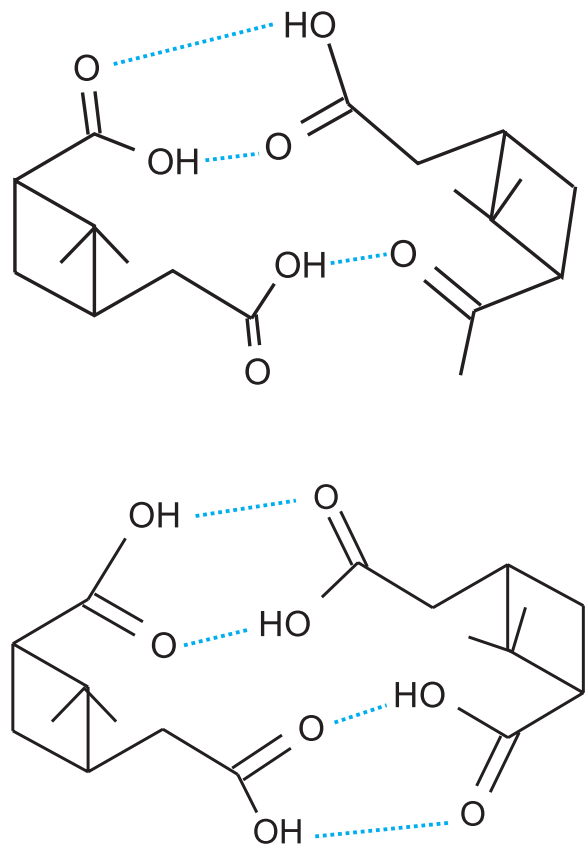

Fig. 8. Structure of the pinic acid/pinonic acid adduct (top) and of the pinic acid dimer (bottom). The hydrogen bonds between nucleating species are represented in blue.

hydroxy carboxylic acids such as pinic acid and hydroxy pinonic acid are the least volatile compounds, with estimated vapour pressures of $3 \times 10^{-6}$ and $6 \times 10^{-7}$ torr, respectively. Other primary products can be considered as semi-volatile, with $\mathrm{p}_{L}^{0}$ ranging between $1 \times 10^{-5}$ and $1 \times 10^{-3}$ torr. Among them, hydroxy hydroperoxides present the lowest vapour pressures. Compounds produced after several oxidation steps in the $\alpha$-pinene mechanism may have low volatilities due to their increased number of functionalities. However, they are expected to contribute less significantly to the aerosol phase because of their lower yields. Hydroperoxides are expected to contribute more largely to SOA formation at low temperatures due to the strong dependence of the hydroperoxy group contribution with temperature. In any case, the contribution of these semi-volatile products to the aerosol phase is expected to be less important than predicted by Bonn et al. (2004). The dimerization of multifunctional carboxylic acids is believed to take place in laboratory experiments of $\alpha$-pinene oxidation. Since dimers are expected to contribute largely to the total (dimer+monomer) concentration of multifunctional carboxylic acids in these conditions, their partial vapour pressure is likely to be close to the vapour pressure measured in the laboratory for these compounds. The pinic/pinonic acid adduct is likely to play a significant role in the observed partitioning of pinonic acid (Yu et al., 1999) between the aerosol and gas phases, due to its low vapour pressure estimated in this study $\left(\leq 1 \times 10^{-6}\right.$ torr $)$. However, the role of dimers and adducts remains difficult to quantify 
in absence of kinetic data for their stabilities and formation rates.

Acknowledgements. This work has been carried out in the framework of the Belgian research programme on Global Change and Sustainable Development, funded by the Belgian Federal Science Policy Office. The authors thank J. Peeters for valuable discussions about the dimerization of carboxylic acids.

Edited by: W. E. Asher

\section{References}

Asher, W. E., Pankow, J. F., Erdakos, G. B., and Seinfeld, J. H.: Estimating the vapor pressures of multi-functional oxygencontaining organic compounds using group contribution methods, Atmos. Environ., 36, 1483-1498, 2002.

Bilde, M. and Pandis, S. N.: Evaporation Rates and Vapor Pressures of Individual Aerosol Species Formed in the Atmospheric Oxidation of $\alpha$ - and $\beta$-pinene, Environ. Sci. Technol., 35, 3344-3349, 2001.

Bilde, M., Svenningsson B., Monster, J., and Rosenorn, T.: EvenOdd Alternation of Evaporation Rates and Vapor Pressures of C3-C9 Dicarboxylic Acid Aerosols, Environ. Sci. Technol., 37, 1371-1378, 2003.

Bonn, B., von Kuhlmann, R., and Lawrence, M. G.: High contribution of biogenic hydroperoxides to secondary organic aerosol formation, Geophys. Res. Lett., 31, L10108, doi:10.1029/2003GL019172, 2004.

Bruckmann, P. W. and Willner, H.: Infrared Spectroscopic Study of Peroxyacetyl Nitrate (PAN) and Its Decomposition Products, Environ. Sci. Technol., 17, 352-357, 1983.

Capouet, M., Peeters, J., Noziere, B., and Muller, J.-F.: Alphapinene oxidation by $\mathrm{OH}$ : simulations of laboratory experiments, Atmos. Chem. Phys., 4, 2285-2311, 2004.

Daubert, T. E. and Danner, R. P.: Physical and Thermodynamic Properties of Pure Chemicals, National Standard Reference Data Systems Parts 1-4, American Institute of Chemical Engineering, Hemisphere, New York, 1989.

Engineering Sciences Data Unit Ltd: Vapour pressures and critical points of liquids. Glycols and cyclic diols, item No 95002, vol. 2d(ii), ESDU international, London, 2001.

Fischer, R. G. and Ballschmiter, K.: Determination of vapor pressure, water solubility, gas-water partition coefficient $P_{G W}$, Henry's law constant, and octanol-water partition coefficient $P_{O W}$ of 26 alkyl dinitrates, Chemosphere, 36, 2891-2901, 1998.

Fredenslund, A., Gmehling, J., and Rasmussen, P.: Vapor-Liquid Equilibria Using UNIFAC: A Group Contribution Method., Elsevier, Amsterdam, 1977.

Griffin, R. J., Dabdub, D., and Seinfeld, J. H.: Develoment and initial evaluation of a dynamic species-resolved model for gas phase chemistry ans size-resolved gas/particle partitioning associated with secondary aerosol formation, J. Geophys. Res., 110, D05304, doi:10.1029/2004JD005219, 2005.

Guenther, A., Hewitt, C. N., Erickson, D., Fall, R., Geron, C., Graedel, T., Harley, P., Klinger, L., Lerdau, M., McKay, W. A., Pierce, T., Scholes, B., Steinbrecher, R., Tallamraju, R., Taylor, J., and Zimmerman, P.: A global model of natural volatile or- ganic compound emissions, J. Geophys. Res., 100, 8873-8892, 1995.

Hallquist, M., Wängberg, I., and Ljungström, E.: Atmospheric fate of carbonyl oxidation products originating from $\alpha$-pinene and $\Delta^{3}$-carene: Determination of rate of reaction with $\mathrm{OH}$ and $\mathrm{NO}_{3}$ radicals, UV absorption cross sections, and vapor pressure, Environ. Sci. Technol., 31, 3166-3172, 1997.

Hoffmann, T., Odum, J. R., Bowman, F., Collins, D., Klockow, D., Flagan, R. C., and Seinfeld, J. H.: Formation of organic aerosols from the oxidation of biogenic hydrocarbons, J. Atmos. Chem., 26, 189-222, 1997.

Hoffmann, T., Bandur, R., Marggraf, U., and Linscheid, M.: Molecular composition of organic aerosols formed from $\alpha$-pinene $/ \mathrm{O}_{3}$ reaction: Implications for new particle formation processes, J. Geophys. Res., 103, 25 569-25 578, 1998.

HSDB (Hazardous Substances Data Bank): National Library of Medicine (NLM) Toxicology Data Network (TOXNET), 2004, Available online at http://toxnet.nlm.nih.gov.

Jenkin, M. E.: Modelling the formation and composition of secondary organic aerosol from $\alpha$-pinene and $\beta$-pinene ozonolysis using MCM v3, Atmos. Chem. Phys., 4, 1741-1757, 2004.

Jensen, T., Fredenslund, A., and Rasmussen, P.: Pure-component vapor pressures using UNIFAC group contribution, Ind. and Eng. Chem., Fundamentals, 20, 239-246, 1981.

Joback, K. G. and Reid, R. C.: Estimation of pure-component properties from group-contributions, Chem. Eng. and Com., 57, 233243, 1987.

Kamens, R., Jang, M., Chien, C. J., and Leach, K.: Aerosol Formation from the Reaction of $\alpha$-pinene and Ozone Using a Gas-Phase Kinetics-Aerosol Partitioning Model, Environ. Sci. Technol., 33, 1430-1438, 1999.

Kanakidou, M. , Seinfeld, J. H., Pandis, S. N., Barnes, I., Dentener, F. J., Facchini, M. C., Van Dingenen, R., Ervens, B., Nenes, A., Nielsen, C. J., Swietlicki, E., Putaud, J. P., Balkanski, Y., Fuzzi, S., Horth, J., Moortgat, G. K., Winterhalter, R., Myhre, C. E. L., Tsigaridis, K., Vignati, E., Stephanou, E. G., and Wilson, J.: Organic aerosol and global climate modelling: a review, Atmos. Chem. Phys., 5, 1053-1123, 2005.

Knauth, P. and Sabbah, R.: Energetics of intra- and intermolecular bonds in $\omega$-alkanediols.II. Thermochemical study of 1,2Ethanediol, 1,3-Propanediol, 1,4-Butanediol and 1,5-Pentanediol at 298.15 K, Struc. Chem., 1, 43-46, 1990a.

Knauth, P. and Sabbah, R.: Energetics of intra- and intermolecular bonds in $\omega$-alkanediols.III. Thermochemical study of 1,6-hexanediol, 1,7-heptanediol, 1,8-octanediol, 1,9-nonanediol, and 1,10-decanediol at 298,15 K, Canad. J. Chem., 68, 731734,1990b.

Knauth, P. and Sabbah, R.: Energetics of inter- and intramolecular bonds in Alkanediols.IV. The Thermochemical study of 1,2-Alkanediols at 298,15 K, Thermochim. Acta, 164, 145-152, 1990c.

Kuckelmann, U., Warscheid, B., and Hoffmann, T.: On-line Characterization of Organic Aerosols Formed from Biogenic Precursors Using Atmospheric Pressure Chemical Ionization Mass Spectroscopy, Anal. Chem., 72, 1905-1912, 2000.

Li, P., Ma, P. S., Yi, S. Z, Zhao, Z. G., and Cong, L. Z.: A new Corresponding-States Group-Contribution method (CSGC) for estimating vapor pressures of pure compounds, Fluid Phase Equi., 101, 101-119, 1994. 
Lide, D. R.: CRC Handbook of Chemistry and Physics, 82th edition, CRC Press, Boce Raton, Fla, 2001.

Makar, P. A.: The estimation of organic gas vapour pressure, Atmos. Environ., 35, 961-974, 2001.

Marrero, J., and Gani R., Group-contribution based estimation of pure component properties, Fluid Phase Equilibria, 183-184, 183-208, 2001.

Myrdal, P. B. and Yalkowsky, S. H.: Estimating pure component vapor pressures of complex organic molecules, Ind. and Eng. Chem. Res., 36, 2494-2499, 1997.

Nielsen, T., Platz, J., Granby, K., Hansen, A. B., Skov, H., and Egelov, A. H.: Particulate organic nitrates: Sampling and night/day variation, Atmos. Environ., 32, 14/15, 2601-2608, 1998.

NIST Chemistry WebBook: NIST Standard Reference Database Number 69, National Institute of Standards and Technology, Gaithersburg MD, March 2003, http://webbook.nist.gov, 2003.

Pankow, J. F.: An absorption model of gas/particle partitioning of organic compounds in the atmosphere, Atmos. Environ., 28, 185-188, 1994a.

Pankow, J. F.: An absorption model of gas/aerosol partitioning involved in the formation of secondary organic aerosol, Atmos. Environ., 28, 189-193, 1994b.

Poling, B. E., Prausnitz, J. M., and O'Connell, J. P.: The properties of gases and liquids, McGraw-Hill, New York, USA, 2001.

Prausnitz, J. M.: Molecular Thermodynamics of Fluid-Phase Equilibria, Prentice-Hall, Englewoods Cliffs, 1969.

Saunders, S. M., Jenkin, M. E., Derwent, R. G., and Pilling, M. J.: Protocol for the development of the Master Chemical Mechanism MCM v3 (Part A): Tropospheric degradation of non-aromatic volatile organic compounds, Atmos. Chem. Phys., 3, 161-180, 2003.
Chein-Hsiun, T.: Group-contribution method for the estimation of vapor pressures, Fluid Phase Equilibria, 99, 105-120, 1994.

Olsen, E. and Nielsen, F.: Predicting Vapour Pressures of Organic Compounds from Their Chemical Structure for Classification According to the VOC-Directive and Risk Assessment in General, Molecules, 6, 370-389,2001.

Orlando, J. J. and Tyndall, G. S.: Gas phase UV absorption spectra for peracetic acid, and for acetic acid monomers and dimers (248 K, 298 K), J. Photochem. and Photobiol., 157, 2-3, 161166, 2003.

Peeters, J., Vereecken, L., and Fantechi, G.: the detailed mechanism of the $\mathrm{OH}$-initiated atmospheric oxidation of $\alpha$-pinene: a theoretical study, Phys. Chem. Chem. Phys., 3, 5489-5504, 2001.

Rosenorn, T., Monster, J., Svenningsson, B., and Bilde, M.: Vapor pressures of C3-C9 Dicarboxylic Acid Aerosols, EGS-AGUEUG Joint Assembly, Nice, France, April 2003.

Schwarzenbach, R. P., Gschwend, P. M., and Imboden, D. M.: Environmental Organic Chemistry, Wiley-Interscience, New York, 1993.

Singleton, D. L., Paraskevopoulos, G., and Irwin, R. S.: UV Absorption Cross-Sections of the Monomer and Dimer of Formic Acid (302 K), J. Photochem., 37, 209-216, 1987.

Tobias, H. J., Docherty, K. S., Beving, D. E., and Ziemann, P. J.: Effect of Relative Humidity on the Chemical Composition of Secondary Organic Aerosol Formed from Reactions of 1Tetradecene and $\mathrm{O}_{3}$, Environ. Sci. Technol., 34, 2116-2125, 2000.

Yaws, C. L.: Handbook of Vapor Pressure, Gulf Publishing Company, Houston, 1994.

Yu, J., Cocker III, D. R., Griffin, R. J., Flagan, R. C., and Seinfeld, J. H.: Gas-Phase Ozone Oxidation of Monoterpenes: Gaseous and Particulate Products, J. Atmos. Chem., 34, 207-258, 1999. 